\title{
Effect of Short Term Supplementation of Coenzyme Q10 on Cumulative Pregnancy Rates in Young Infertile Women with Polycystic Ovarian Syndrome
}

Meryem KURU PEKCANa, Aytekin TOKMAKa, D Gülnur ÖZAKŞITa

aDepartment of Obstetrics and Gynecology, Zekai Tahir Burak Women's Health Care Training and Research Hospital, Ankara, TURKEY

Received: 18.03.2019

Received in revised form: 19.04 .2019

Accepted: 24.05.2019

Available online: 13.06 .2019

\section{Correspondence:}

Meryem KURU PEKCAN

Zekai Tahir Burak Women's Health Care

Training and Research Hospital,

Department of Obstetrics and Gynecology,

Ankara, TURKEY

meryemkuru@gmail.com
Copyright $\odot 2019$ by Türkiye Klinikleri

\begin{abstract}
Objective: To investigate the effect of coenzyme Q10 (CoQ10) supplementation on ovulation induction (OI) and intrauterine insemination (IUI) outcomes in polycystic ovary syndrome (PCOS) patients with clomiphene citrate (CC) failure or resistance. Material and Methods: A total of 130 nulliparous infertile patients diagnosed with PCOS were included in this prospective study. The first group of patients who were unable to conceive after the first treatment with CC received CoQ10 treatment at a dosage of $100 \mathrm{mg} / \mathrm{bid}$ for one month (study group). The other group (control group) received no treatment with CoQ10. The two groups were compared with each other in terms of cycle characteristics and success of the treatment for the subsequent three months. Results: The study group included 66 patients and the control group involved 64 patients. No statistically significant differences were observed between the groups in terms of age, body mass index (BMI), and infertility type. All the study participants had previously received similar medical treatments for infertility. Duration of infertility was significantly longer in the study group as compared to that in the control group ( $3.4 \pm 1.5$ vs. $2.9 \pm 1.1$ years). Cumulative pregnancy rates were observed to be $18(27.3 \%)$ and $21(32.8 \%)$ in the study and control group, respectively. Conclusion: Short term CoQ10 supplementation was not found to be an effective adjuvant therapy for cumulative pregnancy rates in young infertile women with PCOS who have undergone ovulation induction with intrauterine insemination. Yet, this treatment may prove to be effective on some other subgroup of women.
\end{abstract}

Keywords: Clinical pregnancy; clomiphene citrate failure; coenzyme Q10; infertility; PCOS

he polycystic ovary syndrome (PCOS) is an endocrinopathy affecting $5 \%$ to $7 \%$ of the women in their reproductive age. ${ }^{1}$ In addition to the effects on the reproductive system, it also causes metabolic and psychological problems. Gonadotropins (GTs) are preferred in patients who do not respond to clomiphene citrate (CC) treatment. However, GT treatment costs are high and require close monitoring. ${ }^{2}$

PCOS has been found to be associated with dysfunction in mitochondria. ${ }^{3}$ Coenzyme Q10 (CoQ10), also known as ubiquinone, is a fat-soluble substance which may additionally be considered as a vitamin. It is a component of the electron transport chain and participates in aerobic cellular respiration, which generates energy in the form of ATP. CoQ10, mainly found in the inner membrane of mitochondria, also possesses antioxidant properties and is used in the treatment of many diseases like cardiovascular disorders and diabetes mellitus. ${ }^{4-6}$ 
CoQ10 has been shown to play a role in the treatment of mitochondrial disorders in animals. ${ }^{7}$ It has been suggested that pre-treatment with CoQ10 leads to improved ovarian response and embryo quality in young women undergoing in-vitro fertilization procedure to improve the decreased ovarian reserves. ${ }^{8}$ It has been observed that the metabolic and endocrine dysfunctions in patients with PCOS improve with the maintenance of CoQ10 as it ameliorates insulin and lipid metabolism. ${ }^{9}$ In addition, CoQ10 reduces oxidative stress, which results in increased lipolysis of triglycerides, thus contributing to endothelial metabolism in a positive manner. ${ }^{10}$

In this regard, the authors hypothesized that CoQ10 supplementation may contribute to improving oocyte quality and ovulation in infertile women with PCOS. Hence, this study aimed to evaluate the effect of CoQ10 supplementation on ovulation induction (OI) and intrauterine insemination (IUI) outcomes in PCOS patients with CC failure.

\section{MATERIAL AND METHODS}

This study was designed as a prospective non-randomized controlled study involving 130 female patients and was conducted between March and August 2016 in a tertiary level maternity hospital in the capital city of Turkey, Ankara. The study protocol was approved by the institutional ethics committee (Date and decision number: 09.29.201562 ) and it conforms to the provisions of the Declaration of Helsinki. Informed consent was obtained from each participant prior to the initiation of the study.

The inclusion criteria were as follows: nulliparous women aged 20 to 35 years affected with PCOS, follicle-stimulating hormone (FSH) levels below $12 \mathrm{mIU} / \mathrm{mL}$, estradiol $\left(\mathrm{E}_{2}\right)$ levels $<80 \mathrm{pg} / \mathrm{mL}$, no history of any additional diseases and, normal hysterosalpingogram and normal spermiogram parameters of the husband. Women who reported the use of multivitamin supplementation, except for folic acid and those who did not wish to undergo the IUI procedure were excluded from the study.
Also, women diagnosed with PCOS according to the revised Rotterdam consensus were eliminated from the study. ${ }^{11}$

The patients in the first group of PCOS, who were unable to conceive even after the first round of treatment with CC in the author's clinic, were administered CoQ10 supplementation at a dose of $100 \mathrm{mg}$ BID for one month (study group), before implementing the next treatment modality. The other group received no treatment with CoQ10 (control group). The patients were then subjected to OI and IUI procedure either until the time they conceived or at least for three months. According to the clinical measures practiced by the authors, CC is employed as the first step in the treatment modality for infertile PCOS patients. Women, who were still not able to conceive, were then treated with GTs as the next step. In CC-resistant (defined as a failure to ovulate even after receiving $150 \mathrm{mg}$ of CC daily for at least three cycles) patients, the authors use CC and GT sequentially for controlled ovarian stimulation. Thus, the patients were subsequently treated with different OI agents, which were customized according to each patient. Multiple clinicians were involved in the treatment of the study participants.

The groups were compared with each other in terms of cycle characteristics and treatment success. Characteristics of the final treatment cycle of each study participant were recorded. Demographic, hormonal [FSH, LH, $\mathrm{E}_{2}$, thyroid stimulating hormone (TSH), prolactin (PRL)] and clinical features of patients were also noted. Transvaginal ultrasonography was used to determine follicular growth and endometrial thickness. Recombinant human chorionic gonadotropin (hCG) at a dose of $250 \mathrm{mcg}$ was administered subcutaneously when the diameter of at least one or two follicles was $\geq 17$ $\mathrm{mm}$. Semen specimens were collected following masturbation and were prepared by the swim up technique. IUI was performed 34-36 h after hCG administration. A single IUI was performed using a flexible intrauterine cannula (TecnoCath insemination catheter, Ankara, Turkey). All patients who were treated with GTs received support in the luteal phase in the form of vaginal progesterone, 
starting on the day of IUI until pregnancy testing. The clinical pregnancy rate was defined as a visualization of a fetal heartbeat at six weeks of pregnancy after IUI.

\section{STATISTICAL ANALYSIS}

Statistical Package for the Social Sciences (SPSS) for Windows (IBM Corp., Amarok NY, USA) was used for data analysis. Kolmogorov-Smirnov test was applied for the normal distribution of continuous variables. Numerical variables were expressed as mean \pm standard deviation or median (minimum-maximum), whichever appropriate. Categorical variables were shown as number (percentage). The mean differences of normally distributed variables between groups were assessed by the parametric Student's t-test while median values of non-normally distributed variables were assessed by the non-parametric Mann-Whitney U test. Differences between categorical variables were evaluated using the Chi-square or Fisher's exact test. A p-value $<0.05$ was considered to be statistically significant.

\section{RESULTS}

The study group included 66 patients while the control group included 64 patients. No statistically significant differences between the groups were observed in terms of age, BMI and infertility type. Duration of infertility was significantly longer in the study group as compared to that in the controls $(3.4 \pm 1.5$ vs. $2.9 \pm 1.1$ years, $\mathrm{p}=0.031)$. The demographics and baseline hormone levels are depicted in Table 1. No significant differences were observed in the baseline hormone parameters (FSH, $\mathrm{LH}, \mathrm{E}_{2}, \mathrm{TSH}$, and PRL) or the existent and previous cycle characteristics (Table 2). The medical treatment previously administered to the patients for infertility was also similar. No relevant side effects were reported in the patients taking CoQ10 treatment. No significant relationship was found between mature follicle size and clinical pregnancy outcomes in either of the groups. Cumulative pregnancy rates were observed to be $18(27.3 \%)$ and 21 (32.8\%) in the study and control group, respectively $(\mathrm{p}=0.491)$.
TABLE 1: Demographics and baseline hormone levels of the patients.

\begin{tabular}{|c|c|c|c|}
\hline Variables & $\begin{array}{c}\text { Study group } \\
\text { (treated with CoQ10) }(n=66)\end{array}$ & $\begin{array}{l}\text { Control group } \\
\qquad(n=64)\end{array}$ & p-value \\
\hline Age (years) & $25.4 \pm 3.8$ & $24.7 \pm 3.6$ & 0.272 \\
\hline $\mathrm{BMI}\left(\mathrm{kg} / \mathrm{m}^{2}\right)$ & $24.7 \pm 4.0$ & $24.2 \pm 4.5$ & 0.461 \\
\hline Primary infertility $n(\%)$ & $57(86.5)$ & $60(93.8)$ & 0.438 \\
\hline Infertility duration (years) & $3.4 \pm 1.5$ & $2.9 \pm 1.1$ & 0.031 \\
\hline Treatment n (\%) & & & 0.059 \\
\hline $\mathrm{CC}+\mathrm{IUI}$ & $48(72.7)$ & $36(56.3)$ & \\
\hline$G T+\mid U I$ & $10(15.2)$ & $21(32.8)$ & \\
\hline$C C+G T+I U I$ & $8(12.1)$ & $7(10.9)$ & \\
\hline$E_{2}(p g / m L)$ & $37.3 \pm 17.4$ & $42.0 \pm 16.9$ & 0.119 \\
\hline FSH (U/L) & $6.8 \pm 1.7$ & $6.6 \pm 1.8$ & 0.475 \\
\hline LH (U/L) & $7.5 \pm 3.9$ & $8.6 \pm 5.1$ & 0.310 \\
\hline Prolactin (ng/mL) & $12.8 \pm 5.2$ & $12.6 \pm 4.9$ & 0.819 \\
\hline $\mathrm{TSH}(\mathrm{U} / \mathrm{L})$ & $2.2 \pm 1.0$ & $2.3 \pm 1.1$ & 0.684 \\
\hline
\end{tabular}

Note: Data are expressed as mean \pm standard deviation and number (percentage). CoQ10: coenzyme Q10, BMI: Body mass index, CC: Clomiphene citrate, GT: Gonadotropin, IUI: Intrauterine insemination, E2: Estradiol, FSH: Follicle stimulating hormone,

LH: Luteinizing hormone, TSH: Thyroid stimulating hormone. A p-value $<0.05$ is considered statistically significant

TABLE 2: Cycle characteristics of the patients in the study and control groups.

\begin{tabular}{|c|c|c|c|}
\hline \multirow[b]{2}{*}{ Variables } & Study group & \multicolumn{2}{|l|}{ Control group } \\
\hline & d with $\operatorname{CoQ} 10)(n=66)$ & $\quad(n=64)$ & p-value \\
\hline Stimulation duration (days) & $14.5 \pm 3.3$ & $14.0 \pm 2.6$ & 0.332 \\
\hline Endometrial thickness on day of $\mathrm{hCG}(\mathrm{mm})$ & $8.6 \pm 2.4$ & $8.6 \pm 1.8$ & 0.658 \\
\hline Current cycle cancellation $n(\%)$ & $5(7.8)$ & $1(1.5)$ & 0.112 \\
\hline Previous $\mathrm{CC}$ cycles & $2(1-6)$ & $3(1-6)$ & 0.931 \\
\hline Previous GT cycle & $0(0-3)$ & $0(0-3)$ & 0.542 \\
\hline Previous IUI & $2(0-6)$ & $2(0-6)$ & 0.092 \\
\hline Previous cycle cancellation $n(\%)$ & & & 0.765 \\
\hline 1 & $5(7.8)$ & $2(3)$ & \\
\hline 2 & $1(1.6)$ & $2(3)$ & \\
\hline 3 & 0 & $1(1.5)$ & \\
\hline $\mathrm{CC}$ dose used $(\mathrm{mg})$ & $50(50-150)$ & $100(50-150)$ & 0.017 \\
\hline GT starting dose (IU) & $37.5(37.5-75)$ & $37.5(25-75)$ & 0.980 \\
\hline GT total dose (IU) & $554 \pm 230$ & $749 \pm 598$ & 0.424 \\
\hline Follicle size $(\mathrm{mm})$ & $17.9 \pm 1.1$ & $18.0 \pm 0.9$ & 0.396 \\
\hline Cumulative pregnancy rate $\mathrm{n}(\%)$ & $21(32.8)$ & $18(27.3)$ & 0.491 \\
\hline
\end{tabular}

Note: Data are expressed as mean \pm standard deviation, median (minimum-maximum) and number (percentage). hCG: Human chorionic gonadotropin, CC: Clomiphene citrate, GT: Gonadotropin, IUI: Intrauterine insemination. A p-value $<0.05$ is considered statistically significant. 


\section{DISCUSSION}

The main goal of this study was to assess the short term effect of CoQ10 supplementation on pregnancy rates in women with PCOS who underwent OI and IUI because of CC failure or resistance. To the best knowledge of the authors, data on the effects of CoQ10 administration on pregnancy rates in women with PCOS are scarce. This study, however, demonstrated that this treatment option is not an effective adjuvant therapy for assessing cumulative pregnancy rates in women with PCOS.

Maternal micronutrient intake affects the developmental phases of pregnancy and, their deficiency negatively affects both, placental development and fetal growth. ${ }^{12,13}$ However, only a little information is available on the most appropriate combination of vitamin or nutrients that may be useful for human reproduction. ${ }^{14}$ Lifestyle factors can also affect fertility and the inappropriate diet may cause subfertility. In one study, a combination of lifestyle factors was found to lower the risk of anovulatory subfertility by $69 \% .{ }^{15}$ A wide range of observational studies have reported that a support in the form of multiple micronutrients increases pregnancy rate. ${ }^{16,17}$ Preconception nutrition is important because it affects critical steps of pregnancy including fertility, implantation, fetal growth, and placental development. ${ }^{12}$ Micronutrient use may be beneficial in preventing some adverse pregnancy outcomes. ${ }^{18}$ The literature reports a few studies stating that micronutrient reinforcement may have beneficial effects. Besides their use as supportive treatment in infertility, some beneficial effects of micronutrient supplementation were also seen in the preconception period. They are cost-effective and well-tolerated drugs with no significant side effects. In the present study, CoQ10 was well tolerated by all patients with no side effects observed.

Mitochondria perform important functions in the fertilization stage and play a significant role in embryonic development. ${ }^{19}$ The fact that oocyte does not increase the number of mitochondria during ripening may result in poor quality embryo development. ${ }^{20,21}$ Mitochondrial disorders also play a role in the development of metabolic disorders (such as diabetes mellitus, cardiovascular diseases, dyslipidemia)..$^{22}$ In animal studies, it was observed that CoQ10 increased reproductive success by $30 \%$. This effect of CoQ10 is directly related to the effect of cellular ATP production in mitochondrialmediated electron transfer in the respiratory chain. In addition, CoQ10 has been shown to improve ovarian function in patients with PCOS who do not respond to CC therapy. ${ }^{23}$

CoQ10 is an oil-soluble antioxidant synthesized in the human body. It protects the ovaries against free radical damage and reduces oxidative stress in the ovary. A study observed that CoQ10treated mice had a significantly higher CoQ10 concentration in their ovaries. ${ }^{22}$ CoQ10 also inhibits lipid peroxidation in the biological membranes. It has the ability to regenerate the oxidized form of vitamin E. Lipoproteins are possibly protected from oxidative damage due to these effects of CoQ10. ${ }^{24}$ CoQ10 behaves like an antiapoptotic, and this is the main mechanism that explains the essential role of CoQ10 in follicular atresia. ${ }^{25}$ The positive effects of CoQ10 use on the developing embryos have also been emphasized in the previous experimental studies. Its use in in-vitro bovine embryo culture resulted in more extensive blastocysts and greater internal cell masses. ${ }^{26}$

In one study, it was reported that combined treatment using CoQ10-CC significantly increases clinical pregnancy rates in women with CC-resistant PCOS. ${ }^{27}$ The CoQ10 group has been associated with an improved ovarian response, which is likely to have a better clinical pregnancy success rate as compared to that of the control group. In contrast to this study, such an effect of CoQ10 treatment in PCOS patients who have previously experienced CC failure or resistance in their OI cycles could not be observed. The patient cohort of the present study was younger and has favorable reproductive features as compared to that in the said study. In the aforementioned study, there was no difference in terms of ovulation and clinical pregnancy rates among the weak and obese PCOS patients in the CoQ10 group. Therefore, in response to CoQ10, it was concluded that body weight had no effect as 
opposed to other OI agents such as GT, and CoQ10 could be added to oral ovulation induction agents such as CC, which is promising in terms of treatment success. CoQ10 and CC combination has been suggested as it is cheap, effective and stimulates follicular development safely in CC-resistant patients. On the contrary, the authors of this study found that CoQ10 treatment is ineffective. This difference may be due to the dose or time of use of CoQ10.

The present study had some limitations. CoQ10 levels in plasma or serum were not evaluated. Also, metabolic parameters and biomarkers of inflammation or gene expression could not be assessed in this study. The other limitations of the present study include the short treatment duration, daily dosage of CoQ10 supplementation and limited follow-up time. The results of this study may be interpreted as negative data because of the inclusion of patients with relatively favorable prognosis. In addition, there are many factors affecting treatment success in infertile women and a causeeffect relationship between CoQ10 supplementation and pregnancy rates cannot be established. However, the authors deliberate that this study presents some valuable clinical information because of its prospective design.

\section{CONCLUSION}

This study demonstrates that short term CoQ10 supplementation is not an effective adjuvant therapy for cumulative pregnancy rates in young in- fertile women with PCOS who have previously undergone OI with IUI. However, it is quite possible that this treatment would prove to be effective in another subgroup of women. Therefore, larger prospective randomized studies are needed to test the beneficial effects of CoQ10 on the treatment success of infertile women with PCOS.

\section{Acknowledgement}

We would like to thank all the participants and clinic staff.

\section{Source of Finance}

During this study, no financial or spiritual support was received neither from any pharmaceutical company that has a direct connection with the research subject, nor from a company that provides or produces medical instruments and materials which may negatively affect the evaluation process of this study.

\section{Conflict of Interest}

There exists no conflict of interest between the authors and/or family members of the scientific and medical committee members or members of the potential conflicts of interest, counseling, expertise, working conditions, shareholding and similar situations in any form.

\section{Authorship Contributions}

Idea/Concept: Meryem Kuru Pekcan; Design: Meryem Kuru Pekcan, Aytekin Tokmak; Control/Supervision: Gülnur Özakşit; Data Collection and/or Processing: Meryem Kuru Pekcan, Gülnur Özakşit; Analysis and/or Interpretation: Meryem Kuru Pekcan, Aytekin Tokmak; Literature Review: Meryem Kuru Pekcan, Aytekin Tokmak; Writing the Article: Meryem Kuru Pekcan, Aytekin Tokmak; Critical Review: Gülnur Özakşit, Aytekin Tokmak.

\section{REFERENCES}

1. Asunción M, Calvo RM, San Millán JL, Sancho J, Avila S, Escobar-Morreale HF. A prospective study of the prevalence of the polycystic ovary syndrome in unselected Caucasian women from Spain. J Clin Endocrinol Metab. 2000;85(7):2434-8. [Crossref] [PubMed]

2. Hull MG. Epidemiology of infertility and polycystic ovary disease: endocrinological and demographic studies. Gynecol Endocrinol. 1987;1(3):235-45. [Crossref] [PubMed]

3. May-Panloup P, Chretien MF, Malthiery $Y$, Reynier P. Mitochondrial DNA in the oocyte and the developing embryo. Curr Top Dev Biol. 2007;77:51-83. [Crossref]
4. Digiesi V, Cantini F, Oradei A, Bisi G, Guarino GC, Brocchi A, et al. Coenzyme Q10 in essential hypertension. Mol Aspects Med. 1994;15 Suppl:S257-63. [Crossref]

5. Kolahdouz Mohammadi R, HosseinzadehAttar MJ, Eshraghian MR, Nakhjavani M, Khorami E, Esteghamati A. The effect of coenzyme Q10 supplementation on metabolic status of type 2 diabetic patients. Minerva Gastroenterol Dietol. 2013;59(2):2316.

6. Lee BJ, Yen CH, Hsu HC, Lin JY, Hsia S, Lin PT. A significant correlation between the plasma levels of coenzyme Q10 and vitamin B-6 and a reduced risk of coronary ar- tery disease. Nutr Res. 2012;32(10):751-6. [Crossref] [PubMed]

7. Bentov $Y$, Esfandiari $N$, Burstein $E$, Casper RF. The use of mitochondrial nutrients to improve the outcome of infertility treatment in older patients. Fertil Steril. 2010;93(1):2715. [Crossref] [PubMed]

8. Xu Y, Nisenblat V, Lu C, Li R, Qiao J, Zhen $X$, et al. Pretreatment with coenzyme Q10 improves ovarian response and embryo quality in low-prognosis young women with decreased ovarian reserve: a randomized controlled trial. Reprod Biol Endocrinol. 2018;16(1):29. [Crossref] [PubMed] [PMC] 
9. Amin MM, Asaad GF, Abdel Salam RM, El-Abhar HS, Arbid MS. Novel CoQ10 antidiabetic mechanisms underlie its positive effect: modulation of insulin and adiponectine receptors, Tyrosine kinase, PI3K, glucose transporters, SRAGE and visfatin in insulin resistant/diabetic rats. PLoS One. 2014;9(2): e89169. [Crossref] [PubMed] [PMC]

10. Suksomboon N, Poolsup N, Juanak N. Effects of coenzyme Q10 supplementation on metabolic profile in diabetes: a systematic review and meta-analysis. J Clin Pharm Ther. 2015;40(4):413-8. [Crossref] [PubMed]

11. The Rotterdam ESHRE/ASRM-sponsored PCOS Consensus Workshop Group. Revised 2003 consensus on diagnostic criteria and long-term health risks related to polycystic ovary syndrome. Fertil Steril. 2004;81(1):1925. [Crossref]

12. Westphal LM, Polan ML, Trant AS. Doubleblind, placebo-controlled study of fertility blend: a nutritional supplement for improving fertility in women. Clin Exp Obstet Gynecol. 2006;33(4):205-8.

13. Brough L, Rees GA, Crawford MA, Morton $\mathrm{RH}$, Dorman EK. Effect of multiple-micronutrient supplementation on maternal nutrient status, infant birth weight and gestational age at birth in a low-income, multi-ethnic population. Br J Nutr. 2010;104(3):437-45. [Crossref] [PubMed]
14. Bedwal RS, Bahuguna A. Zinc, copper and selenium in reproduction. Experientia. 1994;50(7):626-40. [Crossref]

15. Chavarro JE, Rich-Edwards JW, Rosner BA, Willett WC. Use of multivitamins, intake of $B$ vitamins, and risk of ovulatory infertility. Fertil Steril. 2008;89(3):668-76. [Crossref] [PubMed] [PMC]

16. Lim SS, Noakes M, Norman RJ. Dietary effects on fertility treatment and pregnancy outcomes. Curr Opin Endocrinol Diabetes Obes. 2007;14(6):465-9. [Crossref] [PubMed]

17. Mier-Cabrera J, Genera-García M, De la JaraDíaz J, Perichart-Perera O, Vadillo-Ortega F, Hernandez-Guerrero C. Effect of vitamins C and $E$ supplementation on peripheral oxidative stress markers and pregnancy rate in women with endometriosis. Int J Gynaecol Obstet. 2008;100(3):252-6. [Crossref] [PubMed]

18. Ebisch IM, Thomas CM, Peters WH, Braat DD, Steegers-Theunissen RP. The importance of folate, zinc and antioxidants in the pathogenesis and prevention of subfertility. Hum Reprod Update. 2007;13(2):163-74. [Crossref] [PubMed]

19. Cummins JM. The role of mitochondria in the establishment of oocyte functional competence. Eur J Obstet Gynecol Reprod Biol. 2004;115 Suppl 1:S23-9. [Crossref] [PubMed]

20. May-Panloup P, Chretien MF, Malthiery $Y$, Reynier P. Mitochondrial DNA in the oocyte and the developing embryo. Curr Top Dev Biol. 2007;77:51-83. [Crossref]

21. Victor VM, Rocha M, Bañuls C, Sanchez-Serrano M, Sola E, Gomez M, et al. Mitochondrial complex I impairment in leukocytes from polycystic ovary syndrome patients with insulin resistance. J Clin Endocrinol Metab. 2009;94(9):3505-12. [Crossref] [PubMed]

22. Luce K, Weil AC, Osiewacz HD. Mitochondrial protein quality control systems in aging and disease. Adv Exp Med Biol. 2010;694:108-25. [Crossref] [PubMed]

23. Turunen M, Olsson J, Dallner G. Metabolism and function of coenzyme $Q$. Biochim Biophys Acta. 2004;1660(1-2):171-99. [Crossref] [PubMed]

24. Bentinger M, Brismar K, Dallner G. The antioxidant role of coenzyme $\mathrm{Q}$. Mitochondrion. 2007;7 Suppl:S41-50. [Crossref] [PubMed]

25. Ochiai A, Itagaki S, Kurokawa T, Kobayashi M, Hirano T, Iseki K. Improvement in intestinal coenzyme Q10 absorption by food intake. Yakugaku Zasshi. 2007;127(8):1251-4. [Crossref] [PubMed]

26. Gosden RG. Oogenesis as a foundation for embryogenesis. Mol Cell Endocrinol. 2002;186(2):149-53. [Crossref]

27. El Refaeey A, Selem A, Badawy A. Combined coenzyme Q10 and clomiphene citrate for ovulation induction in clomiphene-citrateresistant polycystic ovary syndrome. Reprod Biomed Online. 2014;29(1):119-24. [Crossref] [PubMed] 